\title{
Control of a Small Wind Turbine in the High Wind Speed Region
}

\author{
Carlos Lumbreras, Student Member, IEEE, Juan M. Guerrero*, Member, IEEE, Pablo García, \\ Member, IEEE, Fernando Briz, Senior Member, IEEE, and David Reigosa, Member, IEEE, \\ Electrical and Computer Engineering Department - University of Oviedo \\ Campus de Viesques Ed. Dept. Oeste n², 33204 Gijon (Spain) \\ Tel: +34-985182531 e-mail: *guerrero@uniovi.es
}

\begin{abstract}
This paper proposes a new soft-stalling control strategy for grid-connected small wind turbines operating in the high and very high wind speed conditions. The proposed method is driven by the the rated current/torque limits of the electrical machine and/or the power converter, instead of the rated power of the connected load, which is the limiting factor in other methods. The developed strategy additionally deals with the problem of system startup preventing the generator from accelerating to an uncontrollable operating point under a high wind speed situation. This is accomplished using only voltage and current sensors, not being required direct measurements of the wind speed nor the generator speed. The proposed method is applied to a small wind turbine system consisting of a permanent magnet synchronous generator and a simple power converter topology. Simulation and experimental results are included to demonstrate the performance of the proposed method. The paper also shows the limitations of using the stator back-emf to estimate the rotor speed in permanent magnet synchronous generators connected to a rectifier, due to significant $d$-axis current at high load.
\end{abstract}

\section{INTRODUCTION}

Renewable energy generation and integration are important topics not only from an electrical engineer perspective but also from a social perspective, due to environmental, economic and strategic reasons. For small consumers, the interest in energy self-production is growing due to the rise of the electricity price, specially in countries without gas and oil production. One of the more affordable and efficient technologies to produce electricity for residential or small business consumers are small wind turbines [1]-[3].

Small wind turbine systems can inject the energy directly into the grid [4]-[13] or store the captured energy in batteries [14]-[20]. The system presented in this paper is intended for grid-tied operation. Different power converter topologies have been proposed for the case of grid-tied applications [21]-[24]. The most widely used converter topology on the generator side for low-power grid-tied systems consists of a diode rectifier and a boost converter [5]-[11], [25]. Alternatively a boost rectifier has also been proposed [26]. An active rectifier with only three active switches was proposed in [19]. To interface the generating system with the grid, either an $\mathrm{H}$ bridge inverter [4]-[7] or three phase phase inverter [9][11] can be used. With the aim of reducing the number of power components in the passive rectifier plus boost converter plus H-bridge configuration, a special back-to-back inverter was proposed in [27]. However, that solution implies a more complex control and the need of a shaft position sensor. To avoid the use of a shaft position sensor using such topology, a sensorless controller was developed in [13]. The simplest topology based on the passive rectifier, boost rectifier and $\mathrm{H}$-bridge converter is used in the present study.

One of the challenges in the operation of small wind turbines is the control and protection under high wind speeds. Whenever the wind power exceeds the turbine power rating, the turbine must be operated below its maximum efficiency point to prevent damage. Some braking mechanism must be enabled if the wind power excess is too high. Pitch control, furling control, stall control, mechanical brakes and electric brakes have been proposed for this purpose [16], [28]. The electric brake using a crowbar to shortcut the generator windings to produce a high braking torque is the preferred option for small wind turbines, due to its simplicity and reduced cost. However, this method has some drawbacks, including a high torsional torque in the turbine shaft and large currents in the generator windings, which can eventually damage the system. To avoid the activation of the crowbar or the use of more complex methods, soft-stall control was proposed for small wind turbines [8], [14], [20], [25], [29] to limit the extracted power to the demanded power by the load. Soft-stall methods operate the turbine at a non-optimal tip speed ratio (TSR) to decrease the power extracted from the wind.

The proposed soft-stall methods [8], [14], [20], [25], [29] consider that a high wind speed condition is produced when there is a mismatch between the maximum wind power that can be extracted with the turbine and the load demand. Therefore, the TSR is reduced to make the extracted power equal to the load power. Those methods assume that the generator drive (i.e. generator and power converter) can always produce a torque to counteract the torque produced by the wind turbine. Nevertheless, in grid connected applications, assuming a strong grid, the maximum power that can be extracted will only be imposed by the rated power of the generating system. In this case, the relevant variable that must be kept under control in terms of high wind speed protection is the turbine torque rather than the turbine power. A high wind speed is here considered that producing some torque above the rated value of the generator drive within the operating generator speed range. This paper proposes a soft-stall method to maintain the turbine generating during high wind speed conditions without connecting the crowbar.

In some situations, the torque exerted by the wind turbine will surpass the maximum value of the generator drive, and the crowbar (or a mechanical brake) will be unavoidable activated to stop the turbine. Once the turbine is stopped, a strategy for its restart is needed. This is not obvious, as low cost systems do not include wind speed sensors. Commercial micro-turbines often wait a short period of time 


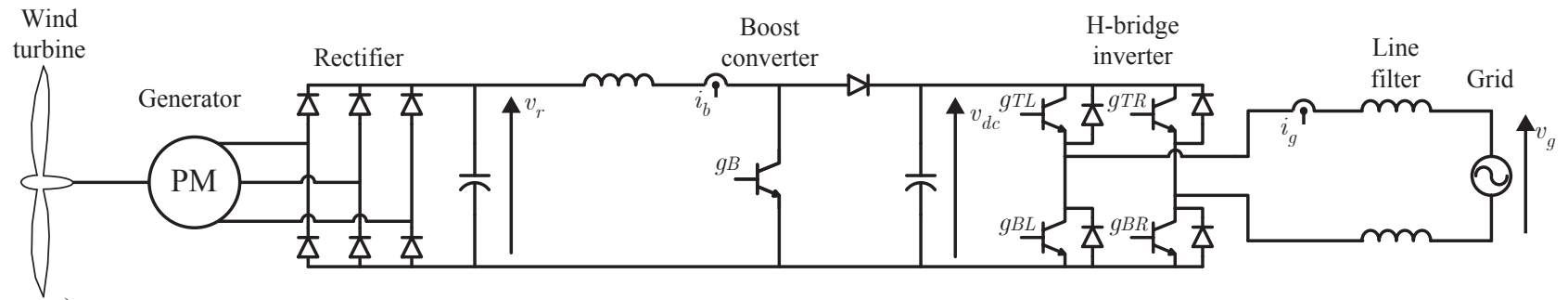

a)

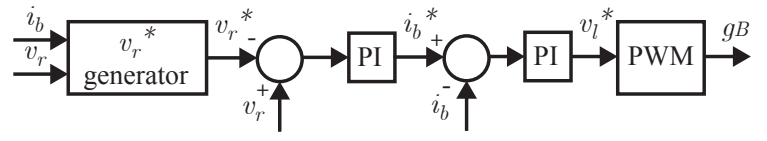

b)

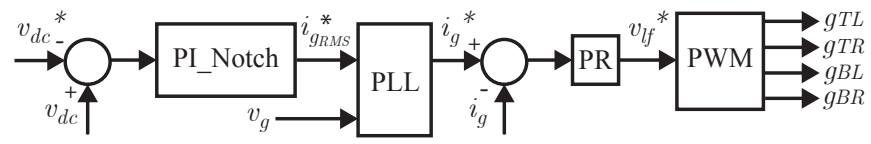

c)

Fig. 1. Schematic representation of the wind energy generation system: a) Wind turbine, generator and power converter; b) Block diagram of the boost converter control system; c) Block diagram of the H-bridge converter control system.

before restarting whenever the electrical brake is activated. If the wind speed remains too high, the wind turbine starts and stops repeatedly, which stresses and can eventually damage the system in the long term. On the contrary, disconnecting the wind turbine longer than needed obviously has a negative economic impact. The proposed method allows automatic reconnection by maintaining the turbine operating at low speed while the wind speed remains high. This reduces both the mechanical and electrical stress over the generating system and additionally increases the energy harvested from the wind. However, the economic improvement of the latter will be ultimately dictated by the number of high wind speed events along the year and the electricity price.

The developed method has two unique and distinctive characteristics: 1) It is driven by the rated current/torque limits of the electrical machine and/or the power converter, instead of the rated power of the connected load; 2) It deals with the problem of system startup during a high wind speed situation. The method uses only current and voltage sensors which are typically available in low-cost microwind turbines, being therefore a cost-effective solution. The method has been simulated and implemented on a $2.5 \mathrm{~kW}$ wind generator system, consisting of a permanent magnet synchronous generator (PMSG), a diode rectifier, a boost DC/DC converter and a $\mathrm{H}$-bridge inverter for single-phase grid connection. It is noted however that the proposed concept is also applicable to other machine designs and power converter topologies.

\section{SYSTEM DESCRIPTION}

Fig. 1 shows a schematic representation of the system. It consists of a wind turbine directly coupled to a three-phase PMSG and an integrated power converter. The hardware components seen in Fig. 1a are described in this section, while the control loops shown in Fig. 1b-c will be described in sections III and IV.

\section{A. Wind turbine}

A fixed-pitch wind turbine has been used in the present study. Table I summarizes some characteristic turbine parameters. The power extracted by a wind turbine depends on the wind speed, the constructive parameters of the turbine, and the rotor speed (1),

$$
P=\frac{1}{2} \rho A_{R} c_{p}(\lambda, \vartheta) v_{w}^{3}
$$

TABLE I. TURBINE PARAMETERS

\begin{tabular}{|l|c|}
\hline Rated power output & $1.2 \mathrm{~kW}$ \\
\hline Rated wind speed & $12 \mathrm{~m} / \mathrm{s}$ \\
\hline Rated rotor speed & $600 \mathrm{rpm}$ \\
\hline Turbine radius, $R$ & $0.875 \mathrm{~m}$ \\
\hline Turbine inertia constant & $0.74 \mathrm{~kg} \cdot \mathrm{m}^{2}$ \\
\hline Optimal TSR, $\lambda_{\max }$ & 4.6 \\
\hline Optimal power coeffcient, $c_{p_{2} \max }$ & 0.47 \\
\hline
\end{tabular}

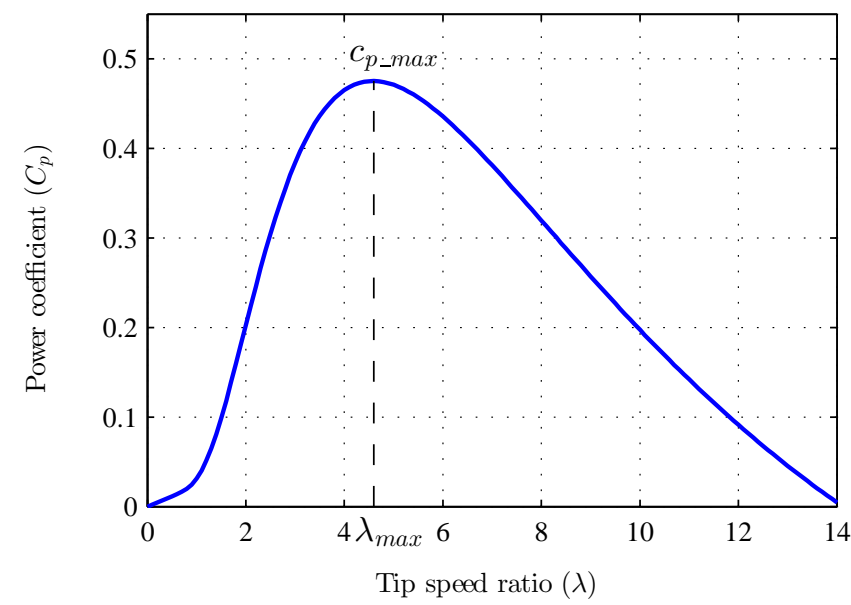

Fig. 2. Power coefficient of the wind turbine as a function of the tip speed ratio.

where $P$ is the extracted power, $\rho$ is the air density, $A_{R}$ is the swept area, $R$ is the turbine radius, $c_{p}$ the power coefficient, $\lambda=\left(\omega_{r m} R\right) / v_{w}$ the tip speed ratio (TSR), $\vartheta$ the blades pitch angle, $\omega_{r m}$ the rotor mechanical speed, and $v_{w}$ the wind speed.

However, the power coefficient depends only on the tip speed ratio in fixed-pitch turbines. This power coefficient can be approximated by a nonlinear function whose parameters can be estimated from experimental data [30]. Steady-state power vs. rotor speed experimental data provided by the turbine manufacturer, including wind speeds up to $26 \mathrm{~m} / \mathrm{s}$, have been used in the present study to obtain the power coefficient curve seen in Fig. 2, where $c_{p \_\max }$ is the maximum power coefficient obtained with the optimal tip speed ratio $\lambda_{\max }$.

The curve seen in Fig. 2 has been used both in simulations and in the wind turbine emulator to obtain the power 
TABLE II. PMSG PARAMETERS

\begin{tabular}{|l|c|}
\hline Rated power & $2.5 \mathrm{~kW}$ \\
\hline Rated current & $3.7 \mathrm{~A}$ \\
\hline Maximum current & $10 \mathrm{~A}$ \\
\hline Rated voltage & $400 \mathrm{~V}$ \\
\hline Rated speed & $700 \mathrm{rpm}$ \\
\hline Pole number & 12 \\
\hline Magnets' voltage constant $K_{e}$ & $1.188 \mathrm{~V} \mathrm{pk} / \mathrm{rpm}$ \\
\hline Stator resistance $R_{s}$ & $6.03 \Omega$ \\
\hline Stator inductance $L_{s}$ & $0.063 \mathrm{H}$ \\
\hline Rotor inertia constant & $0.00581 \mathrm{~kg} \cdot \mathrm{m}^{2}$ \\
\hline
\end{tabular}

and torque exerted by the turbine at different wind speeds, including high wind speeds. The model presents the following limitations:

- The effect of passive stall over the turbine blades at high wind speed is not considered. This provides a worst case scenario to the present study from the point of view of high wind speed protection, since the actual torque at high wind speeds would be smaller than the predicted by the model.

- Dynamic stall effects are not included in the model. Therefore, the torque variations due to excursions from the static power coefficient when the wind speed changes can be seen as disturbances for the proposed control system.

- Considerations about the possible mechanical stresses, vibrations, and system mechanical or structural failure are not covered in this paper. The study is focused in the protection of the electrical subsystem.

\section{B. Permanent magnet synchronous generator (PMSG) and rectifier}

A PMSG whose parameters are shown in Table II is used to perform the electro-mechanical conversion. It is directly coupled to the wind turbine shaft without a gearbox. The machine produces a three-phase voltage, $E$, at no load whose magnitude and frequency change proportionally to the rotor speed of the machine (2), with $K_{e}$ being the backelectromotive force constant and $\omega_{r}$ the rotor speed.

$$
E=K_{e} \omega_{r}
$$

When the machine is loaded, the output voltage decreases due to the stator impedance, the model given by (3) is often used, where $\omega_{r}$ is the rotor speed, $V_{g e n}$ is the phase-to-phase rms voltage and $I_{g}$ is the rms phase current. This model is then combined with the rectifier model to obtain the rectifier voltage and to map the power-speed curves to power-voltage ones [5], [8], [20].

$$
V_{g e n}=E-I_{g}\left(R_{s}+j \omega_{r} L_{s}\right)
$$

However, that model is not accurate since the current vector is not necessary orthogonal to the back-emf voltage vector of the machine when a passive rectifier is used, mainly due to the presence of the input capacitor. Therefore, some $d$ axis current is produced, weakening the machine flux and decreasing the back-emf. That makes the voltage seen by the rectifier smaller than the value provided by (3). Obtaining analytical expressions for this voltage drop is not straightforward. This problem was overcome by characterizing the combined behavior of the PMSG and the rectifier by means of numerical simulation. Several rotor speeds and current levels were imposed to the PMSG and the corresponding rectifier

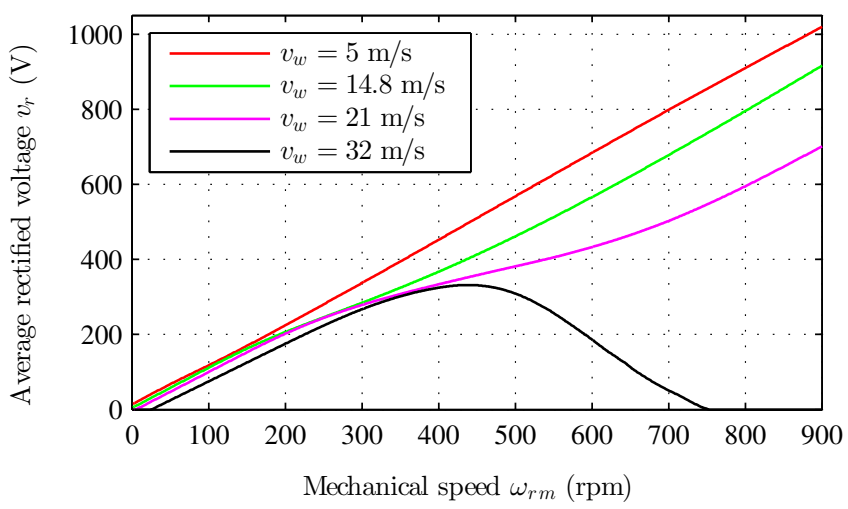

Fig. 3. Average output rectifier voltage $\left(v_{r}\right)$ vs. generator speed $\left(\omega_{r m}\right)$ when this speed is sustained by the generator for different wind speeds.

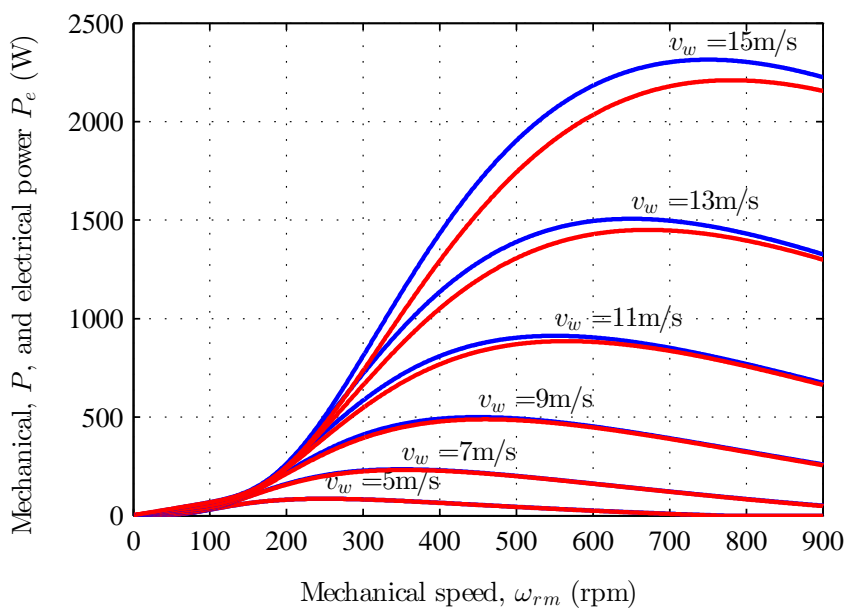

Fig. 4. Turbine (blue) and generator (red) power as a function of the turbine rotor speed $\left(\omega_{r m}\right)$ and wind speed $\left(v_{w}\right)$.

output voltage and the exerted torque were obtained. The simulations showed a significant $d$-axis component of the stator current vector when the boost current increases. Fig. 3 shows the relationship between the generator speed and the rectifier voltage when the boost current needed to match the torque produced by the turbine at different wind speeds is drawn from the generator. It is clearly seen in Fig. 3 that the voltage drop of the stator voltage cannot be only explained by the stator impedance due to the nonlinear behavior of the voltage drop as the wind speed (i.e. current level) increases.

Fig. 4 shows the steady-state power versus rotor speed curves of the turbine for different wind speeds. The electrical power that can be extracted from the rectifier is inferior to the mechanical power due to the generator losses, as can be seen in Fig. 4. This produces a displacement of the actual maximum power point trajectory (MPPT).

Since the mechanical speed is not measured, the electrical power versus the rectifier voltage curves can be used instead for MPPT, as can be seen in Fig. 5. The dotted line shows the actual MPPT, while the segmented line is the approximated MPPT used by the MPPT controller. The cut-in wind speed is set to $5 \mathrm{~m} / \mathrm{s}$ corresponding to a rectifier voltage of $280 \mathrm{~V}$, termed $V_{R_{-} M I N} . V_{R_{-} M A X}$ is the maximum rectifier output voltage the system can withstand. This limit is imposed by the rated voltage of the input capacitors and the power devices. 


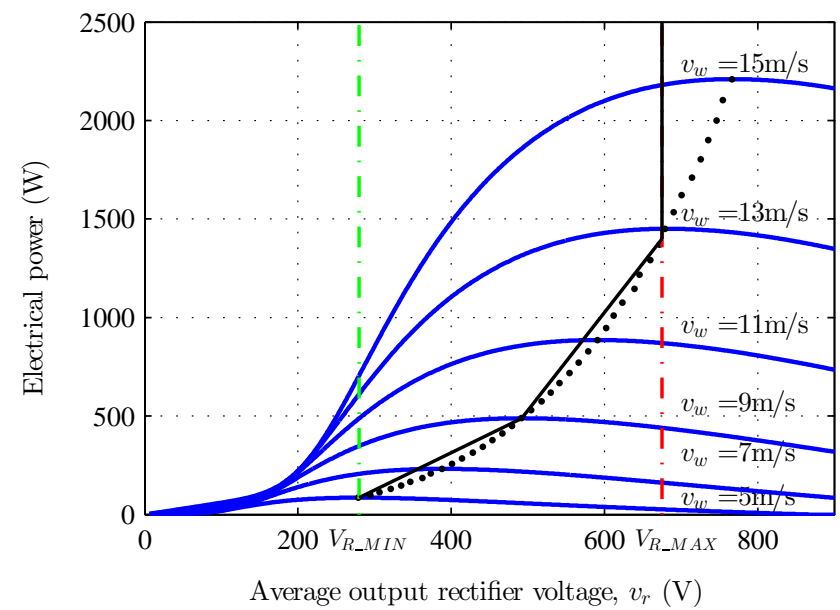

Fig. 5. Electrical power versus rectifier output voltage curves for different wind speeds showing the maximum power point trajectory (dotted line), and the approximated trajectory used for control (straight line segments).

TABLE III. BOOST CONVERTER PARAMETERS

\begin{tabular}{|l|c|}
\hline Input capacitance & $62.5 \mu \mathrm{F}$ \\
\hline Output capacitance & $235 \mu \mathrm{F}$ \\
\hline Boost inductor inductance & $5 \mathrm{mH}$ \\
\hline Boost inductor resistance & $1 \Omega$ \\
\hline
\end{tabular}

Beyond that voltage the system cannot follow the MPPT.

In order to implement and effective turbine protection, the current/torque versus rectifier voltage curves must be carefully analyzed. Fig. 6 shows the current required to produce a generator torque counteracting the turbine torque, in terms of the rectifier voltage for different wind speeds. It is observed in Fig. 6 that the maximum wind speed that can be serviced by the system without exceeding the rated current, $I_{B \_R A T E D}(3.7 \mathrm{~A})$, is $14.8 \mathrm{~m} / \mathrm{s}$. The turbine torque produced by a wind speed of $21 \mathrm{~m} / \mathrm{s}$ can be withstood by the generator by transitory exceeding the rated current to reach the maximum admissible level, $I_{B \_}$MAX (i.e. $10 \mathrm{~A}$ in our system). This limit will depend on the transient overload capacity of the PMSG and of the power electronics and must be selected during the hardware design. Above that wind speed, the turbine can only be controlled at a relatively low rotor speed/rectifier voltage. At the cut-in voltage $V_{R_{-} M I N}$ $(280 \mathrm{~V})$ the generator can withstand sustained wind speeds up to $32 \mathrm{~m} / \mathrm{s}$ by delivering the rated current. If the voltage is reduced to $V_{R \_S A F E}$, sustained wind speeds of up to $35.3 \mathrm{~m} / \mathrm{s}$ can be withstood by the electrical system and keep it generating. Above that level, hurricane wind speeds would require the use of external brake systems (automatic or manual) since they imply sustained torque solicitations beyond the rated torque of the generator. It is again remarked that mechanical or structural failure considerations have not been made in this study.

\section{Power converters and sensors}

The power converter topologies used in this paper have been shown in Fig. 1. The three-phase diode rectifier converts the three-phase voltage supplied by the generator into a DC voltage, $v_{r}$. A boost DC/DC converter is then used to obtain a DC voltage, $v_{d c}$, larger than the rectified grid voltage. The parameters of the boost converter can be found in table III. An H-bridge inverter is used to inject current, $i_{g}$, into the

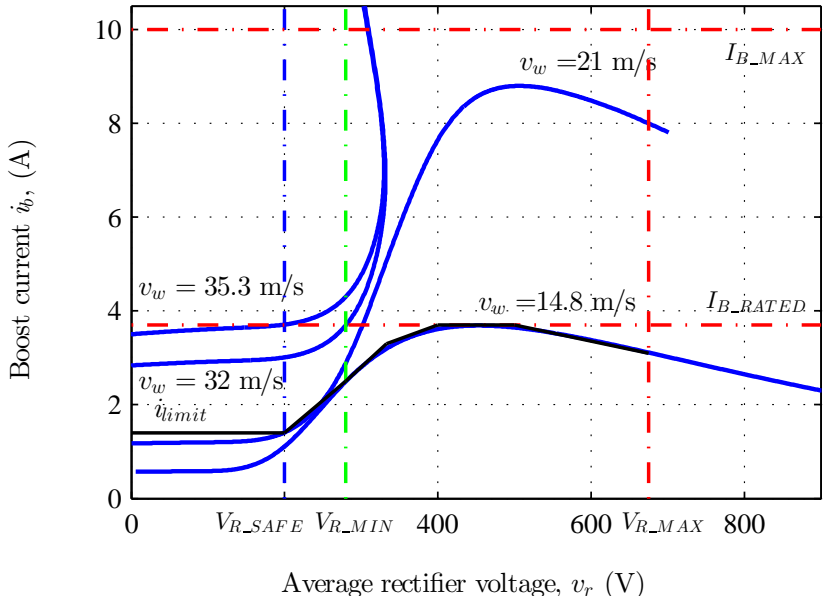

Fig. 6. Current needed to produce the torque to hold the turbine versus rectifier voltage curves for different key wind speeds. Black line shows $i_{\text {limit }}$ values used in over-speed protection.

grid. In order to connect the inverter output with the grid, an inductive line filter is included. This is the most used topology in low-cost grid-tied wind turbines [22]-[24].

A reduced set of variables are measured to control the power converter, as can be seen in Fig. 1. These include the rectifier voltage $v_{r}$, the DC-link voltage $v_{d c}$ the grid voltage $v_{g}$, the boost inductor current $i_{b}$ and the grid current $i_{g}$. Voltages are measured using resistor based sensors while Hall-effect sensors are used to measure the currents.

\section{POWER CONVERTER CONTROL}

Two independent control loops are used to control both the boost converter and the H-bridge inverter, as can be seen in Fig. 1b-c. This section describes the different controllers used and their main control design goals. However, a detailed description about the tuning procedure and the subsystem models is beyond the scope of this paper.

\section{A. Boost converter control}

The wind turbine speed is controlled by the boost DC/DC converter, which demands the current needed to create the required braking torque in the PMSG. The speed of the turbine is indirectly controlled by imposing a rectifier output voltage, $v_{r}$, according to the characterization described in section II-B. The command for the rectifier output voltage, $v_{r}^{*}$, comes from a block that has been called " $v_{r}^{*}$ generator", as can be seen in Fig. 1b, which includes both MPPT and over-speed protection algorithms, as it will be described in section IV.

The rectifier output voltage is controlled using a cascadedcontrol, in which the outer loop controls the rectifier output voltage, $v_{r}$, by commanding a boost current command, $i_{b}^{*}$, to the inner loop controlling the boost converter current. The output of the current controller is the voltage to be imposed to the boost converter inductance, $v_{l}^{*}$, which is translated into a duty command, $g_{B}$, by a PWM generator block. Conventional proportional-integral (PI) controllers (4) are used in both control loops.

$$
P I(s)=k_{p}+\frac{k_{i}}{s}
$$


where $k_{p}$ is the proportional gain, $k_{i}$ is the integral gain, and $s$ the Laplace operator. It is noted that the gains differ for each controller.

The sign in the rectifier output voltage error calculation in Fig. $1 \mathrm{~b}$ is reversed since to increase the rectifier voltage the boost current must be decreased. The boost current controller has been tuned to achieve a $500 \mathrm{~Hz}$ bandwidth with no overshoot in the step response. The rectifier output voltage controller has been tuned to achieve a bandwidth of only 0.1 $\mathrm{Hz}$ with a maximum admissible overshoot of $5 \%$ in the step response. The reason for selecting such a low bandwidth is to approximate the rectifier output voltage dynamics to the turbine/generator speed dynamics.

\section{B. H-bridge converter control}

In order to inject into the grid the same amount of energy that is being extracted from the wind, a power balance is performed in the system trough the DC-link voltage. The DC-link voltage, $v_{d c}$, is set to a fixed reference value, $v_{d c}^{*}$, that can only be kept constant by injecting the appropriate amount of current to the grid, $i_{g}$. The DC-link voltage is controlled with a PI controller augmented with a notch filter (5), as can be seen in Fig. 1c.

$$
P I \_N o t c h(s)=\left(k_{p}+\frac{k_{i}}{s}\right) \frac{s^{2}+2 \xi_{z} \omega_{n} s+\omega_{n}^{2}}{s^{2}+2 \xi_{p} \omega_{n} s+\omega_{n}^{2}}
$$

where $k_{p}$ is the proportional gain, and $k_{i}$ is the integral gain, $\xi_{z}$ and $\xi_{p}$ are the damping coefficients of the notch filter zeros and poles respectively, and $\omega_{n}$ is the central frequency of the filter. It is noted that the controller gains are different to the PI controllers already described.

The notch filter is used to prevent the controller from rejecting the necessary $\mathrm{DC}$ voltage oscillation required to absorb the instantaneous power difference between a threephase system, the PMSG, and a single-phase grid connection. Otherwise this oscillation would be translated to the controller output which is the rms grid current command, $i_{g_{R M S}}^{*}$. The controller has been tuned to achieve a closedloop bandwidth of $40 \mathrm{~Hz}$ with the notch filter providing -20 $\mathrm{dB}$ of attenuation at $100 \mathrm{~Hz}$ (i.e. single-phase instantaneous power pulsation).

In order to achieve unity power factor, the rms grid current command, $i_{g_{R M S}}^{*}$, is synchronized with the grid voltage using a synchronous phase-locked loop (PLL) algorithm [31], shown in Fig. 1c. The instantaneous grid current command, $i_{g}^{*}$, is injected into the grid by means of the H-bridge inverter, controlled by a proportional-resonant (PR) controller (6).

$$
P R(s)=k_{p}+k_{r} \frac{2 \cdot \omega_{r} \cdot s}{s^{2}+\omega_{r}^{2}}
$$

where $k_{p}$ and $k_{r}$ are the proportional and resonant gains respectively, and $\omega_{r}$ is the resonant frequency. The proportional gain has a different value than the controllers previously described.

This type of controller ensures zero tracking error at the resonant frequency which is set to the grid frequency. The controller has been tuned to achieve a closed-loop bandwidth of $500 \mathrm{~Hz}$, a worst case disturbance rejection frequency response of $-30 \mathrm{~dB}$, and a resonant frequency of $50 \mathrm{~Hz}$.

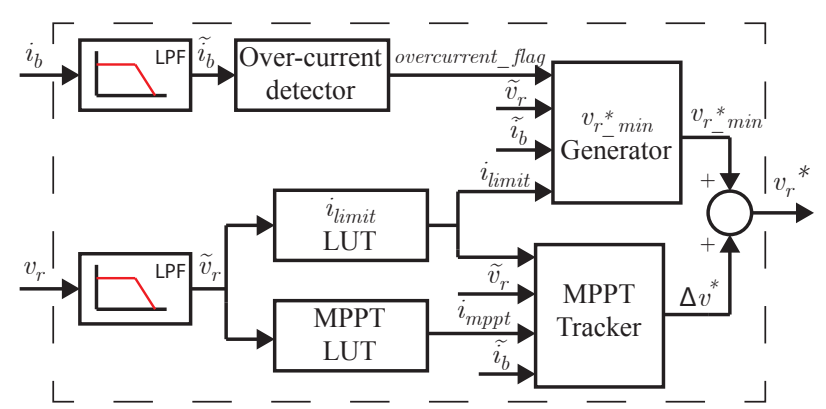

Fig. 7. Voltage reference, $v_{r}^{*}$, generator for MPPT and over-speed protection.

\section{OVER-SPEED CONTROL INTEGRATION}

High rotor speed in the wind turbine can be harmful, as both the turbine and the electronic components can be damaged or destroyed due to mechanical failure or excessive high back-emf voltages. A very high wind speed may produce a torque that could not be counteracted by the generator, eventually resulting in an excessive rotor speed. Some type of protection against high wind speeds is therefore mandatory.

A method to allow the wind turbine to operate safely with high wind speed is proposed in this section. The protection is integrated along with the MPPT control. It is assumed that neither wind speed sensor nor shaft speed sensor are available. The rectifier output voltage will be used to indirectly control the turbine speed according to the curves shown in section II-B.

The block diagram of the proposed protection scheme can be seen in Fig. 7, corresponding with the block " $v_{r}^{*}$ min generator" seen in Fig. 1b. This system will provide a rectifier voltage reference, $v_{r}^{*}$, for the rectifier output voltage PI controller, shown in Fig. 1b. The rectifier voltage reference consists of a constant voltage reference, $v_{r}^{*} \min$ and a variable voltage reference, $\Delta v^{*}$, tracking the maximum power point. Those two commands will be generated by the blocks labeled as " $v_{r \_ \text {min }}^{*}$ generator" and "MPPT Tracker" in Fig. 7. The operation of each block in Fig. 7 is explained following:

\section{A. Low-pass filters}

The rectifier output voltage, $v_{r}$, and the boost current, $i_{b}$, contain a significant amount of ripple due to the switching of the rectifier and of the boost converter. The information contained in the look-up tables that will be described in the following sections is based on average values of both magnitudes. Therefore, lows-pass filtering is applied to both signals to obtain $\tilde{v}_{r}$ and $\tilde{i}_{b}$ respectively. The filters, shown if Fig. 7, are first order low-pass filters (LPF) (7).

$$
\operatorname{LPF}(s)=\frac{\omega_{c o}}{s+\omega_{c o}}
$$

where $\omega_{c o}$ is the cutoff frequency of the filter in rad/s.

The cutoff frequency of the rectifier output voltage filter has been set to $2 \mathrm{~Hz}$, while the the boost current filter has been tuned to $100 \mathrm{~Hz}$.

\section{B. Maximum power point trajectory look-up table}

The MPPT look-up table (LUT) contains an approximation of the actual MPPT of the generating system. Fig. 5 shows the actual MPPT (dotted line) and the approximation used 


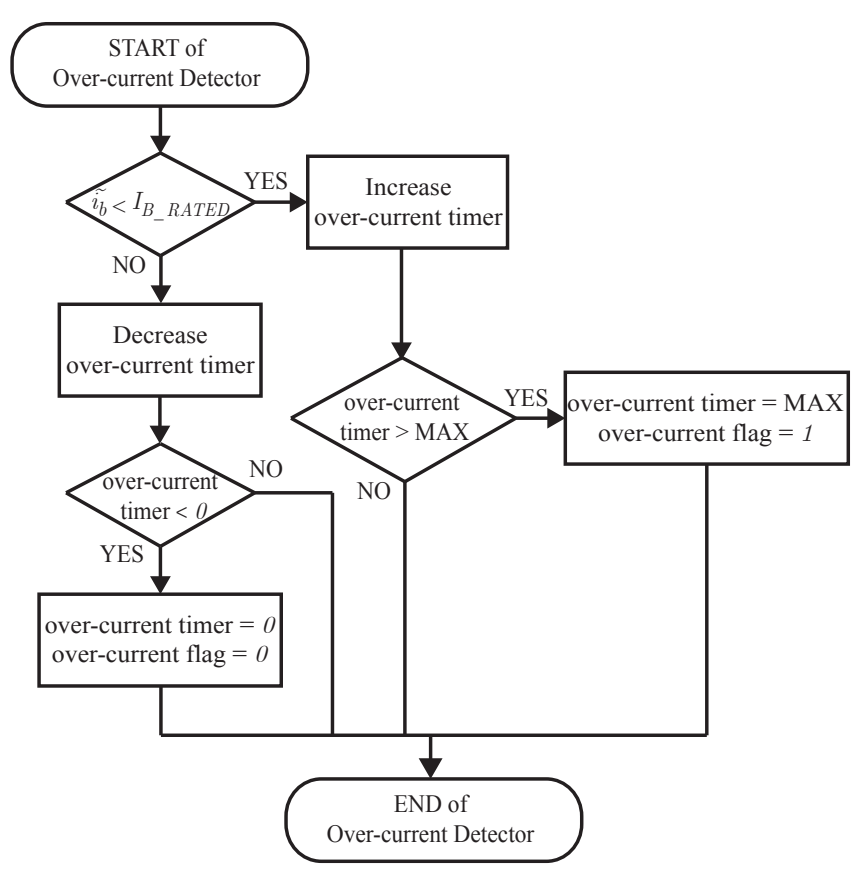

Fig. 8. Over-current detector flow chart.

(straight line segments). This simplification does not introduce meaningful losses in the harvested power in the system under study. If required, a more detailed LUT can be easily generated.

The input for the MPPT LUT block is the filtered rectifier output voltage, $\tilde{v}_{r}$, and the output is the corresponding MPPT current reference, $i_{m p p t}$, instead of the corresponding power magnitude. This current reference is simply obtained by dividing the power obtained from the approximated MPPT line between the filtered rectifier output voltage.

\section{Current limit look-up table}

The " $i_{\text {limit }}$ LUT" block in Fig. 7 provides a current reference to early detect if the wind turbine can surpass the rated torque of the generator at some rotor speed due to the actual wind speed. This reference has been set to approximate the current curve for a wind speed of $14.8 \mathrm{~m} / \mathrm{s}$ in the MPPT region, as can be seen in Fig. 6, since the torque produced by this wind speed can be serviced by the generator at all rotor speeds. If the current delivered by the generator is higher than this limit at some rotor speed at steady-state this will indicate a wind speed higher than $14.8 \mathrm{~m} / \mathrm{s}$. Below $V_{R_{-} M I N}$, the $i_{\text {limit }}$ has been set to a higher value to allow wind speeds up to $21 \mathrm{~m} / \mathrm{s}$ accelerate the turbine to $V_{R \_M I N}$. It must be pointed out that this value is imprecise since during acceleration and deceleration the current delivered must differ for the same wind speed, and it is only used to detect relatively high wind speeds.

\section{Over-current detector}

The "over-current detector" block is an up/down counter that increases whenever the current is larger than the rated value, and decreases if it is smaller. If the counter reaches a pre-established threshold, an over-current flag is set and it will only be reset when the counter returns back to zero. The count up and count down steps can be unevenly selected; in

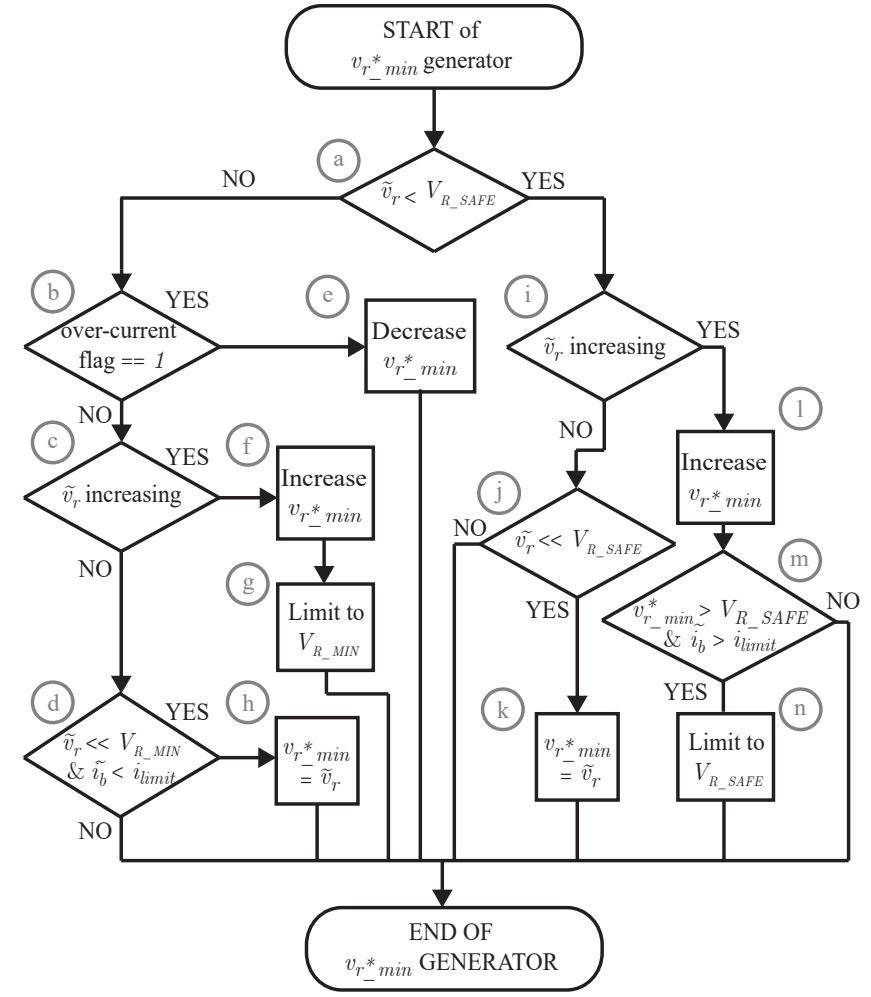

Fig. 9. Flow chart of the minimum voltage reference generator.

the implemented algorithm the count down was set to be four times faster than the count up. The threshold at which the flag is set on is selected in this study by measuring the transient time needed to bring down the voltage from $V_{R_{-} M A X}$ to $V_{R_{-} M I N}$ when the turbine is driven by a wind speed of 21 $\mathrm{m} / \mathrm{s}$, which is the maximum wind speed that can be braked at any rotor speed by temporary surpassing the rated current. The detailed flow chart of this block can be seen in Fig. 8.

\section{E. Minimum rectifier output voltage reference generator}

The " $v_{r \_ \text {min }}^{*}$ generator" block will provide a rectifier voltage ramp command from zero to $V_{R} M_{I N}$, where the system starts tracking the MPPT. The idea behind this reference generator is to have control over the turbine speed/voltage as soon as it starts to rotate, not leaving the turbine to accelerate uncontrolled towards the cut-in voltage, $V_{R_{-} M I N}$. This is necessary to prevent a high wind speed from building up an excessive turbine torque at that voltage level.

The slope of the voltage ramp reference is selected to resemble the voltage increase dynamics produced by a wind speed of $14.8 \mathrm{~m} / \mathrm{s}$. It is recalled that this wind speed is the highest that can be serviced by the system without surpassing the rated current in the whole rotor speed range, as can be seen in Fig. 6. This ramp reference will force the rectifier output voltage controller to brake the turbine from start if the wind speed is higher than $14.8 \mathrm{~m} / \mathrm{s}$. For wind speeds lower than $14.8 \mathrm{~m} / \mathrm{s}$ the controller output will saturate to zero allowing the turbine to accelerate at a rate only imposed by the wind. The process to generate such a ramp is not straightforward since it must be only generated if the wind blows. It can be summarized in the flow chart seen in Fig. 9 and it is explained next. 
When the rectifier output voltage is below $V_{R} S A F E$ (Fig. 9a) the method first checks if the voltage is increasing (Fig. 9i). In that case the voltage command is also increased (Fig. 91). If the new voltage command is above $V_{R \_S A F E}$ and the boost current is higher than $i_{\text {limit }}$ (Fig. $\left.9 \mathrm{~m}\right)$, then the voltage command is limited to $V_{R} S_{S A F E}$ (Fig. 9n). At this point, the reference is maintaine $\bar{d}$ constant whenever the current exceeds $i_{\text {limit }}$. This prevents high speed winds from developing excessive torque at higher rotor speeds. The minimum wind speed at which the turbine operates with reduced rotor speed will depend on the selection of $i_{\text {limit }}$ for the voltage $V_{R \_S A F E}$. With the selection made in this study the implemented protection will prevent the rectifier output voltage, and thus the turbine speed, from increasing when the turbine blades are pushed by a wind speed above $31 \mathrm{~m} / \mathrm{s}$.

If the rectifier output voltage is still or decreasing due to the absence of wind, its magnitude is compared with $V_{R \_S A F E}$ (Fig. 9j). If this value is much smaller than $V_{R} S A F E$ then the voltage command is reset to the actual voltage (Fig. 9k). This reset is necessary to avoid an uncontrolled acceleration if the wind returns. Otherwise the command is kept constant.

Once the rectifier output voltage is above $V_{R_{-} S A F E}$ due to admissible wind speeds, a checking is done on the overcurrent flag provided by the over-current detector (Fig. 9b). If an over-current situation is not detected the voltage increase is checked (Fig. 9c). If the voltage is increasing the voltage command is also increased (Fig. 9f) up to a maximum $V_{R \_M I N}$ (Fig. 9g). In the opposite case the reference is kept constant or made equal to the voltage (Fig. 9h) depending on the voltage and current level (Fig. 9d).

If an over-current situation created by a strong wind is detected, the minimum voltage reference is decreased towards $V_{R} S A F E$ (Fig. 9e). This will make the current to decrease once steady-state is reached.

In case of very high wind speeds, the required current can excess the ultimate limits of the machine and/or power converter. In this case, a crowbar or a mechanical brake must be activated [28] to stop the wind turbine. Since no wind speed information is available, deciding when the wind turbine must be restarted is not trivial, as the wind turbine would start and stop repeatedly if the high wind condition remains. The proposed method overcomes this situation. Once the turbine has been stopped, it can be immediately restarted since the minimum rectifier output voltage reference generator will prevent the turbine from accelerating while the high wind condition remains.

\section{F. MPPT controller}

Once the rectifier output voltage exceeds the cut-in voltage $V_{R}$ MIN , the MPPT block starts producing an additional reference $\Delta v_{r}^{*}$ needed to track the maximum power point. This reference will be increased or decreased depending on whether the boost current is higher or smaller than the $i_{m p p t}$ provided by the MPPT look-up table, as seen in Fig. 7. The voltage step must be selected not to delay the voltage increase nor to speed up the voltage decrease (i.e. not to draw a current much higher than $i_{m p p t}$ ) in the wind speed range never producing a torque above the rated value (i.e. below $14.8 \mathrm{~m} / \mathrm{s}$ in Fig. 6). The detailed flow chart of this control block can be seen in Fig. 10 .

This block also introduce protections against high wind speeds arising during the MPPT operation. If the boost

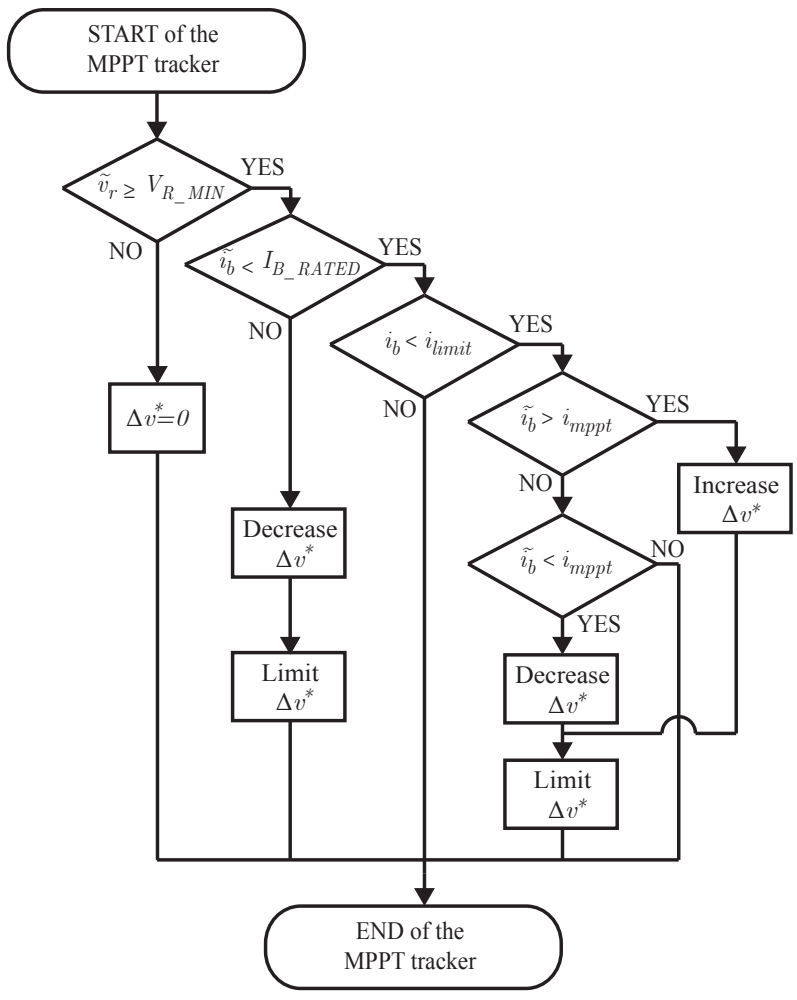

Fig. 10. MPPT controller flow chart.

current is eventually larger than $i_{\text {limit }}$, the voltage reference is held constant. This situation is produced when a wind speed is ideally greater than $14.8 \mathrm{~m} / \mathrm{s}$. In the opposite case, if the MPPT tracker kept increasing the voltage, the current might surpass the rated value at a higher rotor speed. By keeping the voltage command constant (i.e. rotor speed) that situation is avoided.

In the event the current exceeds the rated value due to a high wind speed, the voltage is decreased. This will result in a transitory increase of the current level to achieve a higher torque, reducing the voltage reference and thus, the actual voltage, to $V_{R} M I N$. The voltage slope must be selected to trade-off the maximum peak transient current and the total time needed to reduce the voltage, considering the dynamic limitations imposed by the rectifier output voltage controller. A solution in which the voltage is not required to reduce to $V_{R} M I N$ while maintaining the rated current, is currently being developed. This is accomplished in powerbased stalling methods by adding a delaying filter in the feedback loop [8]. However, the addition of such delay must be carefully studied, since in the event of increasing wind and for high wind conditions, the control of the turbine could be lost.

\section{Simulation Results}

To test the performance of the proposed method, several simulations for different wind conditions were carried out. PSIM software from Powersim was used for this purpose. The turbine, generator, and boost converter parameters used in simulation were the same as for the actual system, shown in tables I, II and III respectively. The power switches for both the boost converter and the H-bridge were modeled as ideal switches, reducing the computational burden. This will 

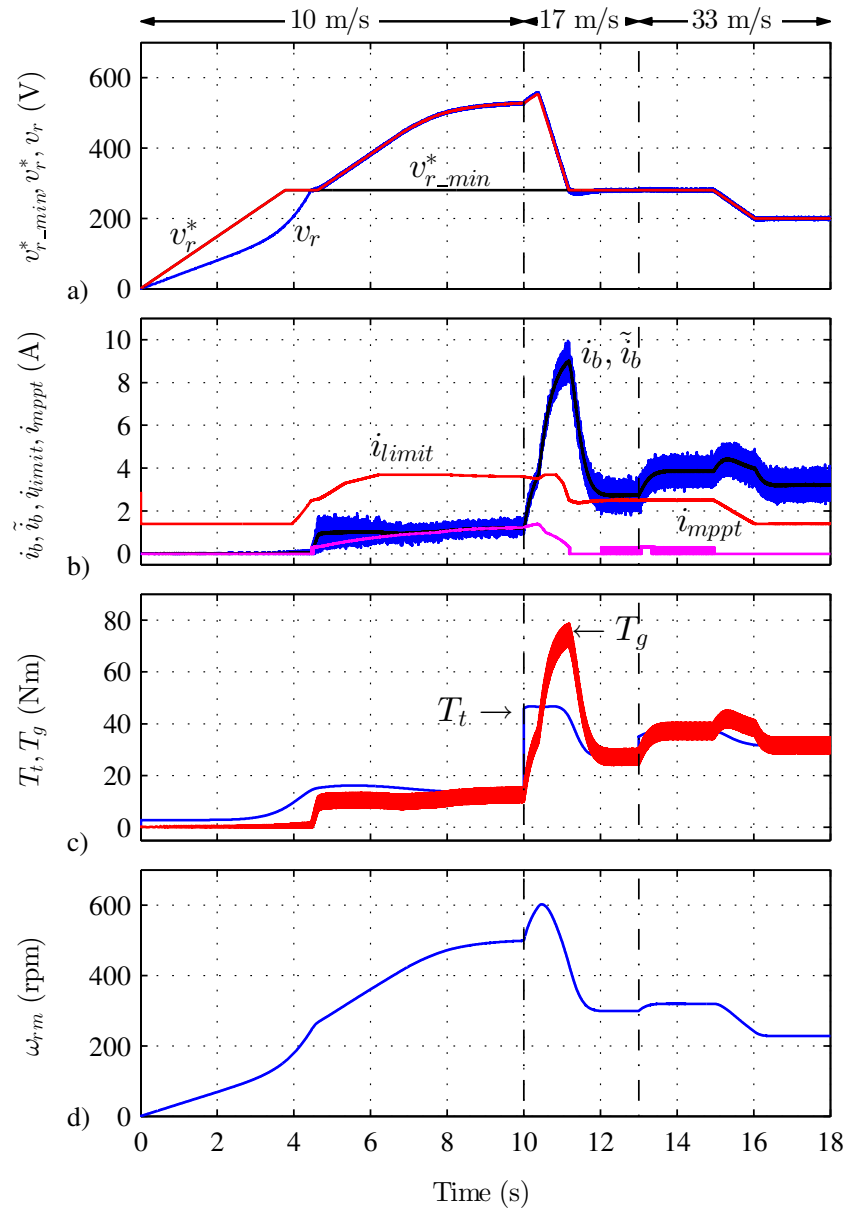

Fig. 11. Simulation result showing the behavior of the proposed method under increasing wind conditions $(10 \mathrm{~m} / \mathrm{s}, 17 \mathrm{~m} / \mathrm{s}$ from $10 \mathrm{~s}$, and $33 \mathrm{~m} / \mathrm{s}$ from 13s): a) rectifier voltage command $\left(v_{r}^{*}\right)$, rectifier voltage $\left(v_{r}\right)$ and minimum rectifier voltage command $\left(v_{r_{\text {min }}}^{*}\right)$; b) boost current $\left(i_{b}\right)$, filtered boost current $\left(\tilde{i}_{b}\right)$, current limit $\left(i_{\text {limit }}\right)$ and MPPT current target $\left(i_{m p p t}\right)$; c) turbine torque $\left(T_{t}\right)$ and generator torque $\left.\left(T_{g}\right) ; \mathrm{d}\right)$ mechanical rotor speed $\left(\omega_{r m}\right)$.

lead to slightly better results in terms of system efficiency than the actual system, but does not have a significant impact for the analysis presented in this paper. The switching and sampling frequency are set to $20 \mathrm{kHz}$ in the boost converter and $10 \mathrm{kHz}$ in the $\mathrm{H}$-bridge inverter. The control loops were implemented in a $\mathrm{C}$ language function block for easiness of portability to the hardware controller.

Two examples including increasing and decreasing wind conditions have been selected to illustrate the behavior of the proposed technique.

\section{A. Increasing wind conditions.}

Fig. 11 shows an example of the turbine behavior under increasing wind conditions starting from rest. The wind speed is $10 \mathrm{~m} / \mathrm{s}$ for $10 \mathrm{~s}$, then it changes to $17 \mathrm{~m} / \mathrm{s}$, and at $13 \mathrm{~s}$ increases again to $33 \mathrm{~m} / \mathrm{s}$. The $17 \mathrm{~m} / \mathrm{s}$ wind speed exemplifies the case of a wind speed that can be always handled by the generator by temporary surpassing the rated torque/current, as can be seen in Fig. 6. A wind speed of $33 \mathrm{~m} / \mathrm{s}$ represents a case that can eventually produce a torque higher than the absolute maximum limit of the turbine, also seen in Fig. 6.
The $10 \mathrm{~m} / \mathrm{s}$ wind speed makes the turbine to accelerate, making a rectifier voltage command $v_{r}^{*}$ to be generated by the $v_{r}^{*}$ min generator block (see Fig. 11a). Since the rectifier voltage command is larger than the actual voltage, no boost current will be commanded to be drawn from the generator (Fig. 11b) and the turbine will speed up at a rate only dictated by the turbine torque (Fig. 11c-d).

When the rectifier voltage reaches the cut-in voltage $\left(V_{R \_} I_{I N}=280 \mathrm{~V}\right)$ the MPPT control block is activated and some current starts to be extracted from the generator. The boost current, $i_{b}$, and the target MPPT current, $i_{m p p t}$, are forced to converge by the MPPT control block, as shown in Fig. $11 b$.

At $10 \mathrm{~s}$, a sudden change of the wind speed from $10 \mathrm{~m} / \mathrm{s}$ to $17 \mathrm{~m} / \mathrm{s}$ occurs. Although such wind speed change is not realistic in practice, it is useful to evaluate the control dynamics, and will be used both for simulation and experimental cases. The new wind speed results in a large increase of the turbine torque that must be counteracted by the generator (Fig. 11c). The required boost current is consequently larger than the rated current and the over-speed control makes the voltage command to decrease to $V_{R_{-} M I N}$ to reduce the speed and thus, the turbine torque (Fig. $11 \mathrm{c}-\mathrm{d}$ ). This makes to further increase the boost current for a while, in order to produce enough torque to brake the turbine. As it was stated before, the system must be designed to withstand a short time overcurrent. At the end of that transient the current is again under the rated value.

At $t=13 \mathrm{~s}$, the wind changes to $33 \mathrm{~m} / \mathrm{s}$. Since this wind speed can be above the controllable limits at a relatively low rotor speed, the voltage command is reduced to $V_{R \_} S A F E$ by the proposed method. This is accomplished by the overcurrent block described in section IV. After measuring a current above the rated value for a predefined time the overcurrent flag is activated making the voltage command to decrease. This can be seen in Fig. 11a-b.

\section{B. Decreasing wind conditions.}

An example of the turbine behavior under decreasing wind conditions starting from rest can be seen in Fig. 12. The wind speed is $30 \mathrm{~m} / \mathrm{s}$ for $4.5 \mathrm{~s}$, then it changes to $21 \mathrm{~m} / \mathrm{s}$, and at $9 \mathrm{~s}$ decreases to $8.5 \mathrm{~m} / \mathrm{s}$. In this case, the $30 \mathrm{~m} / \mathrm{s}$ and $21 \mathrm{~m} / \mathrm{s}$ speeds have been chosen as examples of a wind speed that can exceed the generator maximum capabilities, and a wind speed that can be always handled by transitory surpassing the rated torque, respectively.

The $v_{r \_ \text {min }}^{*}$ generator block detects an increasing voltage from startup and commands a voltage reference that limits the acceleration of the wind turbine, as can be seen in Fig. $12 \mathrm{a}-\mathrm{b}$. Since a current larger than $i_{\text {limit }}$ is required to produce the necessary torque (Fig. 12c), the voltage command is held equal to $V_{R} \_S A F E$ once this value is reached. This operating point will prevent the system from repeated start and hard stop cycles, and will keep the generator producing some power at high wind speed.

At $t=4.5 \mathrm{~s}$, the wind speed decreases to $21 \mathrm{~m} / \mathrm{s}$ and the voltage command increases to reach the cut-in voltage (280V) in which the MPPT mode starts. At that point the voltage command increases in an attempt to make the boost current, $i_{b}$, to match with the $i_{m p p t}$ command. Since that wind speed can produce torque levels higher than rated torque at some rotor speed in the MPPT range, the system must limit the 

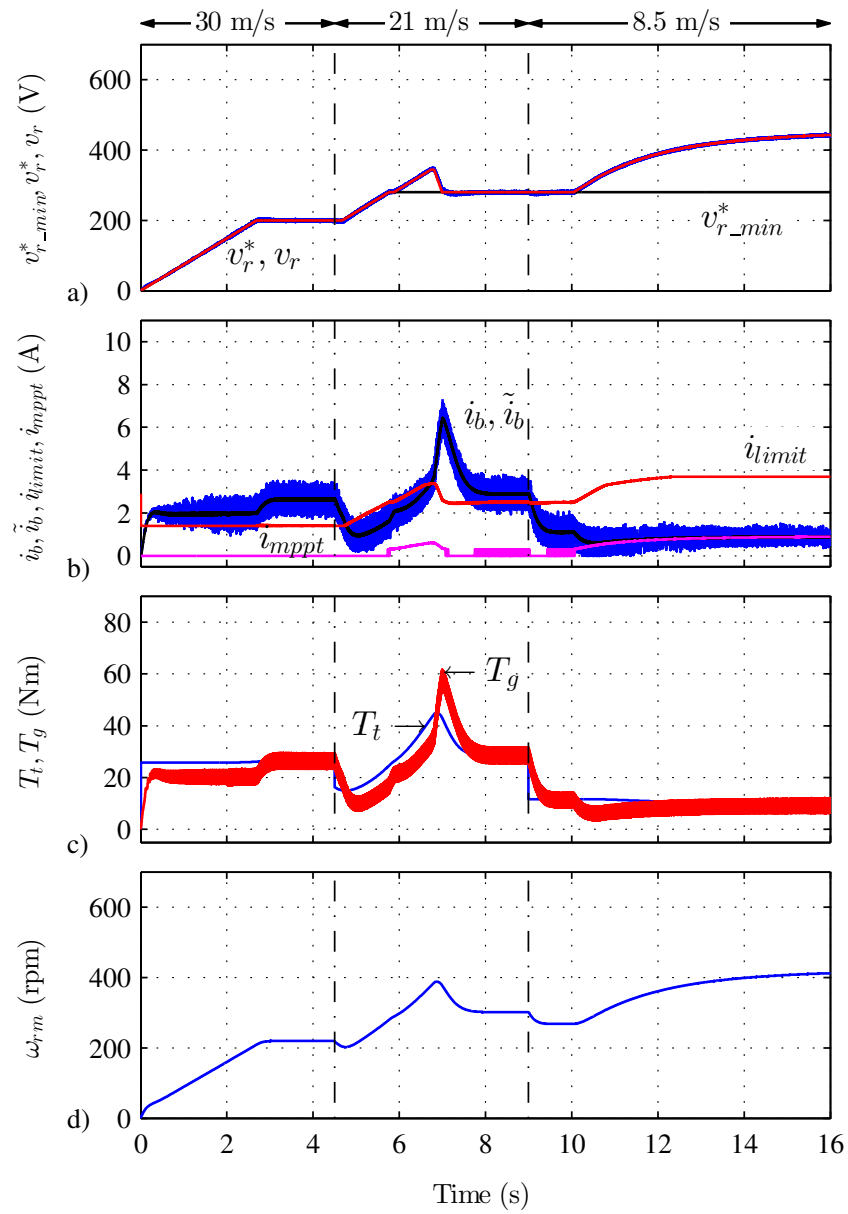

Fig. 12. Simulation result showing the behavior of the proposed method under decreasing wind conditions $(30 \mathrm{~m} / \mathrm{s}, 21 \mathrm{~m} / \mathrm{s}$ from $4.5 \mathrm{~s}$, and 8.5 $\mathrm{m} / \mathrm{s}$ from $7 \mathrm{~s})$ : a) rectifier voltage command $\left(v_{r}^{*}\right)$, rectifier voltage $\left(v_{r}\right)$ and minimum rectifier voltage command $\left(v_{r \text { min }}^{*}\right) ;$ b) boost current $\left(i_{b}\right)$, filtered boost current $\left(\tilde{i}_{b}\right)$, current limit $\left(i_{\text {limit }}\right)$ and MPPT current target $\left(i_{m p p t}\right)$; c) turbine torque $\left(T_{t}\right)$ and generator torque $\left(T_{g}\right)$; d) mechanical rotor speed $\left(\omega_{r m}\right)$.

over-current situation. That event is early detected by the proposed method when the actual current surpasses $i_{\text {limit }}$, as can be seen in Fig. 12b. Then the voltage is decreased to $V_{R \_} I_{I N}$ by transiently surpassing the rated current/torque (Fig. 12b-c). The advantage of the proposed method is that the duration and magnitude of this current transient will be smaller than in case of waiting for the current to surpass the rated value.

The wind speed changes to $8.5 \mathrm{~m} / \mathrm{s}$ at $t=9 \mathrm{~s}$. The boost current drops since a lower torque is required to maintain the turbine speed/rectifier voltage. Therefore, after some predefined time the over-current flag is set to zero and the MPPT control is reactivated. A higher rectifier voltage is then commanded to force to boost current $i_{b}$ to follow the MPPT current command, $i_{m p p t}$, as can be seen in Fig. 12a-b. The simulations show that the method works as intended.

\section{EXPERIMENTAL RESULTS}

The proposed control method has been tested on a prototype system that can be seen in Fig. 13 [7]. The wind turbine in Fig. 1 is emulated using a 4-pole $11 \mathrm{~kW}$ vector controlled induction motor drive, labeled "load motor" in Fig. 13. The

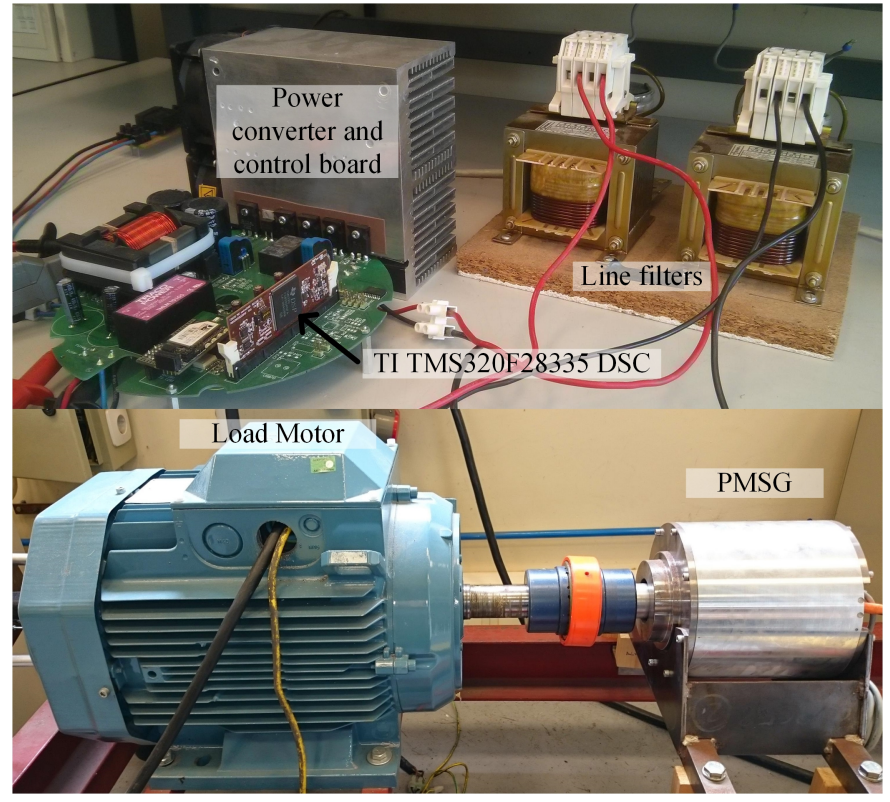

Fig. 13. Prototype of the integrated power converter and control board (top). Load motor and PMSG (bottom).

induction motor is controlled with an Emerson Unidrive SP2403 drive, integrating a SM Applications Lite Module V2 board, programmed to impose a torque in the load motor equivalent to that of the wind turbine of Table I, based on the rotor speed feedback and the commanded wind speed. An 12pole $2.5 \mathrm{~kW}$ Alxion 190STK3M alternator whose parameters can be found in Table II is used as generator. The rated power mismatch between the two machines compensates for the different pole number, making the load motor to be able to produce the necessary torque at low speed. This solution was taken since similar power 12-pole induction motors were not available in the lab. The total inertia of the experimental system is the sum of the generator inertia, shown in Table II, and the induction motor inertia, having a value of $0.091 \mathrm{~kg} \cdot \mathrm{m}^{2}$.

An integrated controller and power converter using the topology shown in Fig. 1, has been built to control the PMSG as can be seen in Fig. 13. This board also includes the current and voltage sensors, only the line filters being external to that board. The board mounts a Texas Instruments (TI) TMS320F28335 digital signal controller (DSC) where all the described control loops and algorithms are implemented. The boost converter parameters are seen in Table III.

As it has been described, the simulation parameters are the same as those of the experimental setup, including the sampling and switching frequencies. It is noted however that two differences exist between the simulation and the experimental setup: 1) the inertia in the experimental setup is significantly smaller than that of the simulation (and the actual wind turbine), 2) the rectifier voltage ramp generator starts once the rectifier voltage reaches $100 \mathrm{~V}$, to overcome some experimental setup limitations at low speed and low torque. It is noted that both differences imply more challenging dynamic operating conditions for the experimental setup case compared to the simulation setup case, but smaller current levels are expected during transients due to the smaller inertia constant.

Experimental results with the same wind changing condi- 

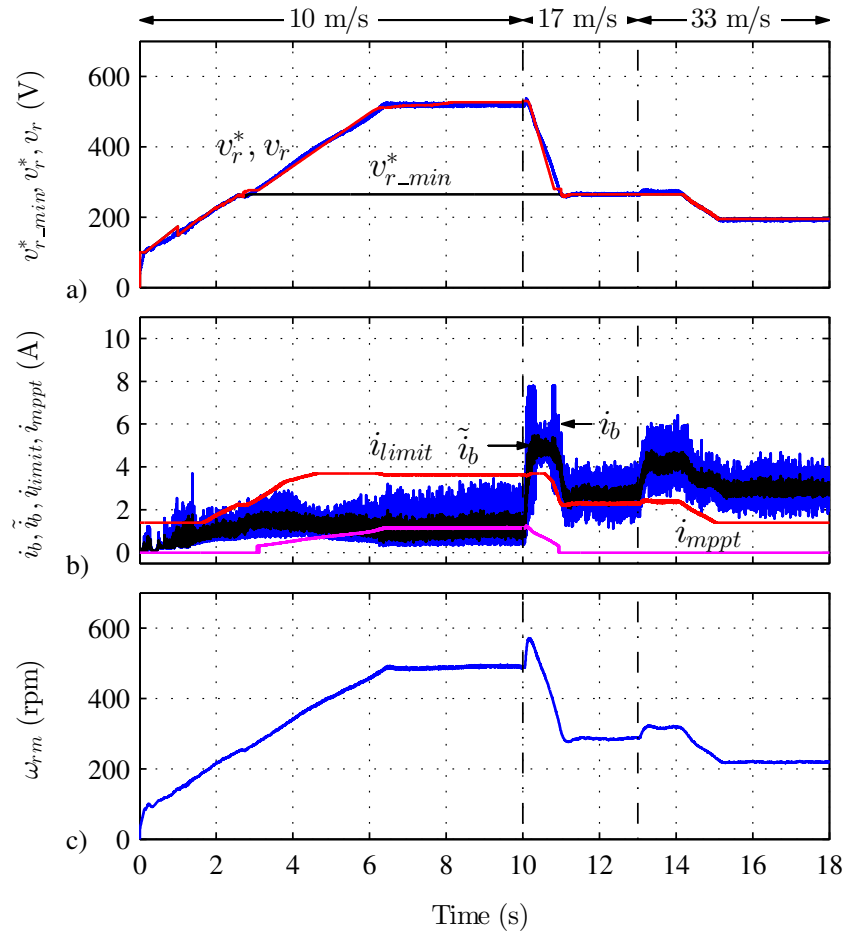

Fig. 14. Experimental results showing the behavior of the propose method under increasing wind conditions $(10 \mathrm{~m} / \mathrm{s}, 17 \mathrm{~m} / \mathrm{s}$ from $10 \mathrm{~s}$, and $33 \mathrm{~m} / \mathrm{s}$ from $13 \mathrm{~s})$ : a) rectifier voltage command $\left(v_{r}^{*}\right)$, rectifier voltage $\left(v_{r}\right)$ and minimum rectifier voltage command $\left(v_{r_{-}}\right.$min $)$; b) boost current $\left(i_{b}\right)$, filtered boost current $\left(i_{b}\right)$, current limit $\left(i_{\text {limit }}\right)$ and MPPT current target $\left(i_{m p p t}\right)$; c) mechanical rotor speed $\left(\omega_{r m}\right)$.

tions as in the simulations are presented here for easiness of comparison.

\section{A. Increasing wind conditions}

Fig. 14 shows the behavior of the system under increasing wind conditions. The results are similar to those of the simulation case of Fig. 11. The main differences come from the reduced inertia constant of the experimental setup. The lower inertia constant makes the acceleration from zero speed much faster than in the simulation case. This makes the voltage controller to demand some current from the beginning to make the rectifier voltage, $v_{r}$, to stick to the voltage command, $v_{r}^{*}$. Once in the MPPT region, the tracking of the MPPT is much faster for the same reason.

When the wind speed changes to $17 \mathrm{~m} / \mathrm{s}$ the same behavior seen in the simulation of Fig. 11 is observed. The only difference is the smaller current effort during transients due to the lower inertia constant.

At $13 \mathrm{~s}$ the wind speed changes to $33 \mathrm{~m} / \mathrm{s}$ and the voltage is reduced to $V_{R_{-} S A F E}$ as in the simulation case. Again, the current demand is smaller due to the smaller inertia.

\section{B. Decreasing wind conditions}

In the test shown in Fig. 15 the wind turbine starts rotating due to a wind speed of $30 \mathrm{~m} / \mathrm{s}$, as in the simulation of Fig. 12. The behavior of the turbine is similar to that shown in the simulation. As in the previous case the main differences come from the fact of having different inertia constants. This makes the transients to be faster and with lower current values than in the simulation tests.
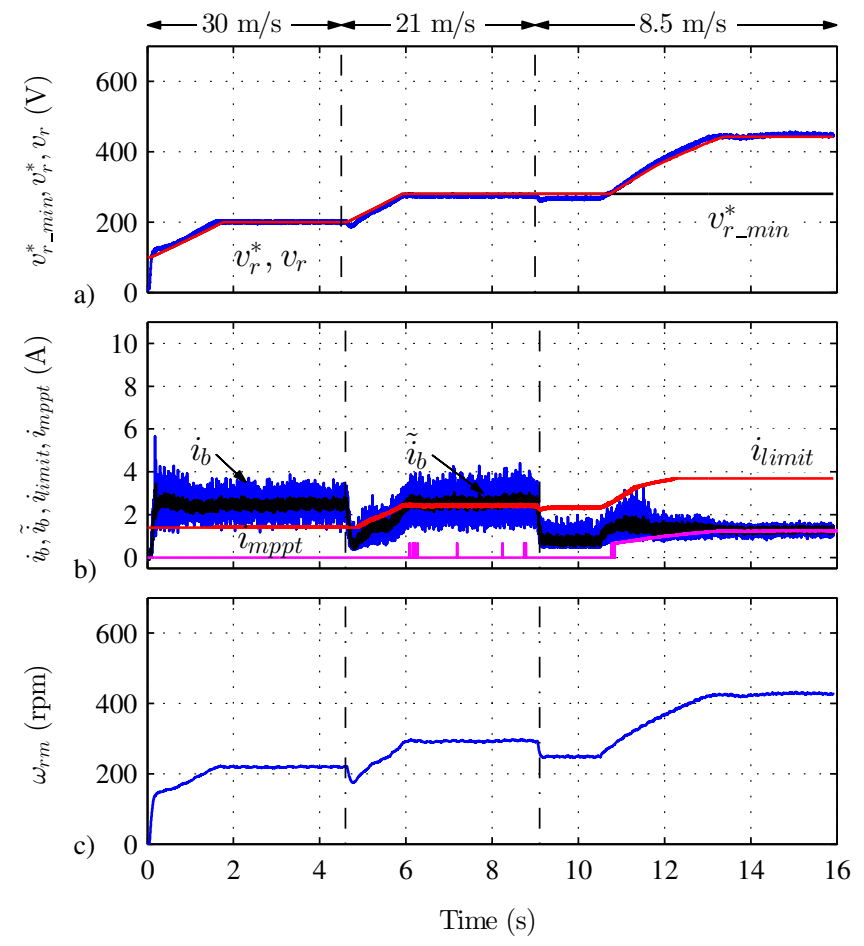

Fig. 15. Experimental results showing the behavior of the propose method under decreasing wind conditions $(30 \mathrm{~m} / \mathrm{s}, 21 \mathrm{~m} / \mathrm{s}$ from $4.5 \mathrm{~s}$, and $8.5 \mathrm{~m} / \mathrm{s}$ from $9 \mathrm{~s})$ : a) rectifier voltage command $\left(v_{r}^{*}\right)$, rectifier voltage $\left(v_{r}\right)$ and minimum rectifier voltage command $\left(v_{r \_ \text {min }}\right)$; b) boost current $\left(i_{b}\right)$,filtered boost current $\left(i_{b}\right)$, current limit $\left(i_{\text {limit }}\right)$ and MPPT current target $\left(i_{m p p t}\right)$; c) mechanical rotor speed $\left(\omega_{r m}\right)$.

It is noted that, in both increasing and decreasing wind condition cases, all the variables reach to values very close to those shown in the simulations at steady-state, proving the practical application of the proposed method.

\section{CONCLUSIONS}

The operation of small wind turbines for domestic or small business use is driven by two factors: cost and almost unsupervised operation. Specially important is the turbine operation and protection under high wind speeds, where the turbine torque can exceed the rated torque of the generator. This paper proposes a soft-stall method to decrease the turbine torque if a high wind speed arises and, as a unique feature, the method is able to early detect a high wind condition at startup keeping the turbine/generator running at low rotor speed avoiding successive start and stop cycles. The proposed method uses only voltage and current sensors typically found in small turbines making it an affordable solution. Both simulation and experimental results demonstrate the validity of the proposed concepts.

This paper also shows that commonly used machine and rectifier models assuming unity power factor do not provide accurate estimations of the generator speed in loaded conditions, even if the resistive and inductive voltage drop are decoupled, due to the significant circulation of $d$-axis current if a PMSG is used. This paper proposes using a pre-commissioned look-up table whose inputs are both the rectifier output voltage and the boost current. 


\section{REFERENCES}

[1] W. Kellogg, M. Nehrir, G. Venkataramanan, and V. Gerez, "Generation unit sizing and cost analysis for stand-alone wind, photovoltaic, and hybrid wind/PV systems," IEEE Transactions on Energy Conversion, vol. 13, no. 1, pp. 70-75, Mar. 1998.

[2] P. Gipe, Wind Power: Renewable Energy for Home, Farm, and Business, 2nd Edition. Chelsea Green Publishing, Apr. 2004.

[3] A. C. Orrell, H. E. Rhoads-Weaver, L. T. Flowers, M. N. Gagne, B. H. Pro, and N. A. Foster, "2013 Distributed Wind Market Report," Pacific Northwest National Laboratory (PNNL), Richland, WA (US), Tech. Rep., 2014. [Online]. Available: http://www.osti.gov/scitech/biblio/1158500

[4] J. Benjanarasut and B. Neammanee, "The d-, q- axis control technique of single phase grid connected converter for wind turbines with MPPT and anti-islanding protection," in 2011 8th International Conference on Electrical Engineering/Electronics, Computer, Telecommunications and Information Technology (ECTI-CON). IEEE, May 2011, pp. 649-652.

[5] M. Arifujjaman, "Modeling, simulation and control of grid connected Permanent Magnet Generator (PMG)-based small wind energy conversion system," in Electric Power and Energy Conference (EPEC), 2010 IEEE, Aug. 2010, pp. $1-6$.

[6] H. Wang, C. Nayar, J. Su, and M. Ding, "Control and Interfacing of a Grid-Connected Small-Scale Wind Turbine Generator," Energy Conversion, IEEE Transactions on, vol. 26, no. 2, pp. 428 -434, Jun. 2011.

[7] C. Lumbreras, J. Guerrero, P. Garcia, F. Briz, and D. Diaz, "Development and testing of a micro-wind generating system," in 2013 International Conference on New Concepts in Smart Cities: Fostering Public and Private Alliances (SmartMILE), Dec. 2013, pp. 1-6.

[8] A. Ahmed, L. Ran, and J. Bumby, "New Constant Electrical Power Soft-Stalling Control for Small-Scale VAWTs," IEEE Transactions on Energy Conversion, vol. 25, no. 4, pp. 1152-1161, Dec. 2010.

[9] S.-H. Song, S. il Kang, and N. kun Hahm, "Implementation and control of grid connected AC-DC-AC power converter for variable speed wind energy conversion system," in Applied Power Electronics Conference and Exposition, 2003. APEC '03. Eighteenth Annual IEEE, vol. 1, 2003, pp. 154-158 vol.1.

[10] Y. Y. Xia, J. E. Fletcher, S. J. Finney, K. H. Ahmed, and B. W. Williams, "Torque ripple analysis and reduction for wind energy conversion systems using uncontrolled rectifier and boost converter," IET Renewable Power Generation, vol. 5, no. 5, pp. 377-386, Sep. 2011.

[11] Y. Xia, K. Ahmed, and B. Williams, "A New Maximum Power Point Tracking Technique for Permanent Magnet Synchronous Generator Based Wind Energy Conversion System," IEEE Transactions on Power Electronics, vol. 26, no. 12, pp. 3609-3620, Dec. 2011.

[12] H.-G. Park, S.-H. Jang, D.-C. Lee, and H.-G. Kim, "Low-cost converters for micro wind turbine systems using PMSG," in 7th Internatonal Conference on Power Electronics, 2007. ICPE '07, Oct. 2007, pp. 483-487.

[13] N. T. Hai, S.-H. Jang, H.-G. Park, and D.-C. Lee, "Sensorless control of PM synchronous generators for micro wind turbines," in Power and Energy Conference, 2008. PECon 2008. IEEE 2nd International, 2008, pp. 936-941.

[14] E. Muljadi, T. Forsyth, and C. P. Butterfield, "Soft-stall control versus furling control for small wind turbine power regulation," National Renewable Energy Lab., Golden, CO (United States), Tech. Rep., 1998. [Online]. Available: http://www.osti.gov/scitech/biblio/661575

[15] S. Jiao, G. Hunter, V. Ramsden, and D. Patterson, "Control system design for a $20 \mathrm{~kW}$ wind turbine generator with a boost converter and battery bank load," in Power Electronics Specialists Conference, 2001. PESC. 2001 IEEE 32nd Annual, vol. 4, 2001, pp. 2203-2206 vol. 4.

[16] Y. Matsui, A. Sugawara, S. Sato, T. Takeda, and K. Ogura, "Braking Circuit of Small Wind Turbine Using NTC Thermistor under Natural Wind Condition," in Power Electronics and Drive Systems, 2007. PEDS '07. 7th International Conference on, Nov. 2007, pp. $910-$ 915.

[17] C.-C. Hua and C.-Z. He, "Design and implementation of a digital power converter for wind energy conversion," in 2011 6th IEEE Con- ference on Industrial Electronics and Applications (ICIEA). IEEE, Jun. 2011, pp. 1398-1402.

[18] K.-Y. Lo, Y.-M. Chen, and Y.-R. Chang, "MPPT Battery Charger for Stand-Alone Wind Power System," IEEE Transactions on Power Electronics, vol. 26, no. 6, pp. 1631-1638, Jun. 2011.

[19] Y.-L. Juan, "An Integrated-Controlled AC/DC Interface for Microscale Wind Power Generation Systems," IEEE Transactions on Power Electronics, vol. 26, no. 5, pp. 1377-1384, May 2011.

[20] J. Chen, J. Chen, and C. Gong, "New Overall Power Control Strategy for Variable-Speed Fixed-Pitch Wind Turbines Within the Whole Wind Velocity Range," IEEE Transactions on Industrial Electronics, vol. 60, no. 7, pp. 2652-2660, Jul. 2013.

[21] Z. Chen, J. Guerrero, and F. Blaabjerg, "A Review of the State of the Art of Power Electronics for Wind Turbines," IEEE Transactions on Power Electronics, vol. 24, no. 8, pp. 1859-1875, Aug. 2009.

[22] Z. Chen, X. Xiao, H. Wang, and M. Liu, "Analysis of converter topological structure for direct-drive wind power system with PMSG," in 2010 International Conference on Power System Technology (POWERCON). IEEE, Oct. 2010, pp. 1-5.

[23] M. Abarzadeh, H. Madadi, and L. Chang, "Power Electronics in Small Scale Wind Turbine Systems," in Advances in Wind Power, R. Carriveau, Ed. InTech, Nov. 2012. [Online]. Available: http://www.intechopen.com/books/advances-inwind-power/power-electronics-in-small-scale-wind-turbine-systems

[24] T. R. De Freitas, P. J. Menegz, and D. S. Simonetti, "Converter topologies for permanent magnetic synchronous generator on wind energy conversion system," in Power Electronics Conference (COBEP), 2011 Brazilian. IEEE, 2011, pp. 936-942. [Online]. Available: http://ieeexplore.ieee.org/xpls/abs_all.jsp?arnumber=6085292

[25] Z. Dalala, Z. Zahid, and J.-S. Lai, "New overall control strategy for wind energy conversion systems in MPPT and stall regions," in 2013 IEEE Energy Conversion Congress and Exposition (ECCE), Sep. 2013, pp. 2412-2419.

[26] O. Castillo, E. Amoros, G. Sanfeliu, and L. Morales, "Average Current Mode Control of Three-Phase Boost Rectifiers with Low Harmonic Distortion Applied to Small Wind Turbines," in Electronics, Robotics and Automotive Mechanics Conference, 2009. CERMA '09., Sep. 2009, pp. $446-451$.

[27] H.-G. Park, S.-H. Jang, D.-C. Lee, and H.-G. Kim, "Low-cost converters for micro wind turbine systems using PMSG," in Power Electronics, 2007. ICPE '07. 7th Internatonal Conference on, 2007, pp. $483-487$.

[28] A. Sugawara, K. Yamamoto, T. Yoshimi, S. Sato, A. Tsurumaki, and T. Ito, "Research for Electric Brake Using NTC Thermistors on Micro Wind Turbine," in Power Electronics and Motion Control Conference, 2006. EPE-PEMC 2006. 12th International, Sep. 2006, pp. 1597 1601.

[29] J. Hui, A. Bakhshai, and P. Jain, "An Energy Management Scheme with Power Limit Capability and an Adaptive Maximum Power Point Tracking for Small Standalone PMSG Wind Energy Systems," IEEE Transactions on Power Electronics, vol. PP, no. 99, pp. 1-1, 2015.

[30] S. Heier, Grid Integration of Wind Energy Conversion Systems, 2nd ed. Wiley, Jun. 2006.

[31] M. Saitou, N. Matsui, and T. Shimizu, "A control strategy of singlephase active filter using a novel d-q transformation," in Industry Applications Conference, 2003. 38th IAS Annual Meeting. Conference Record of the, vol. 2, Oct. 2003, pp. 1222-1227 vol.2. 